ECCOMAS

\section{Proceedia}

COMPDYN 2021

$8^{\text {th }}$ ECCOMAS Thematic Conference on Computational Methods in Structural Dynamics and Earthquake Engineering M. Papadrakakis, M. Fragiadakis (eds.) Streamed from Athens, Greece, 28 - 30 June 2021

\title{
COMPRESSIVE STRENGTH EVALUATION OF BLUE MOSQUE MINARET STONES WITH ULTRASONIC TESTING
}

\author{
G. Uncu ${ }^{1}$, Ş.Ö. Dede ${ }^{2}$, and E. Çaktı ${ }^{3}$ \\ ${ }^{1}$ Phd Candidate, Earthquake Engineering Department, Kandilli Observatory and Earthquake Research \\ Institute, Boğaziçi University, İstanbul \\ e-mail: gulen.uncu@boun.edu.tr \\ ${ }^{2}$ Res. Assistant, Earthquake Engineering Department, Kandilli Observatory and Earthquake Research \\ Institute, Boğaziçi University, İstanbul \\ e-mail: sahin.dede@boun.edu.tr \\ ${ }^{3}$ Prof. Dr, Earthquake Engineering Department, Kandilli Observatory and Earthquake Research Insti- \\ tute, Boğaziçi University, İstanbul \\ e-mail: eser.cakti@boun.edu.tr
}

\begin{abstract}
Engineering modeling and analysis of historical structures include various uncertainties and related difficulties. The most important difficulty is to obtain consistent data of structural materials without damaging historical texture as much as possible. The aim of this study is to determine the average compressive strength of the minarets of the Blue Mosque by means of ultrasonic testing. In the scope of the study, cube samples were collected from the unusable stones that were remained from restoration works carried out in the mosque. Compressive strength tests were performed following ultrasonic tests and a highly correlated relation was obtained. This relation was used in a detailed ultrasonic test study carried out in the minarets of the Blue Mosque and afterward, the mean compressive strength distributions for each minaret were estimated. It is thought that the results of the compressive strength test applied for the first time on the Blue Mosque stones as well as the detailed results for each minaret will make a significant contribution to the literature for future restoration studies and analyses.
\end{abstract}

Keywords: Blue Mosque, compressive strength, non-destructive techniques, cultural heritage, masonry structure 


\section{ULTRASOUND TESTING}

Ultrasound testing is a nondestructive method that uses high frequency sound wave to determine the material properties. It is based on evaluation of the velocities of $\mathrm{P}$ and $\mathrm{S}$ waves which are transmitted and reflected back through the material. This study covers the application of ultrasound testing method on Blue Mosque Minarets in İstanbul, Turkey. The equipment utilized for the application is Proceq Pundit Lab Plus. It consists two probes that transmit and receive the sound waves and a device that displays the obtained value. In this study, two probes are used: $250 \mathrm{kHz}$ probe and $54 \mathrm{kHz}$ probe. The $54 \mathrm{kHz}$ probe only generates $\mathrm{P}$ waves, whereas the $250 \mathrm{kHz}$ can generate both $\mathrm{P}$ and $\mathrm{S}$ waves. As can be seen in Figure 1, there are three types of measurement techniques: direct, semi-direct and indirect. The most reliable one is the direct measurement technique, however it is only applicable when the material thickness is appropriate to transfer the waves through the probes which are located reciprocal.
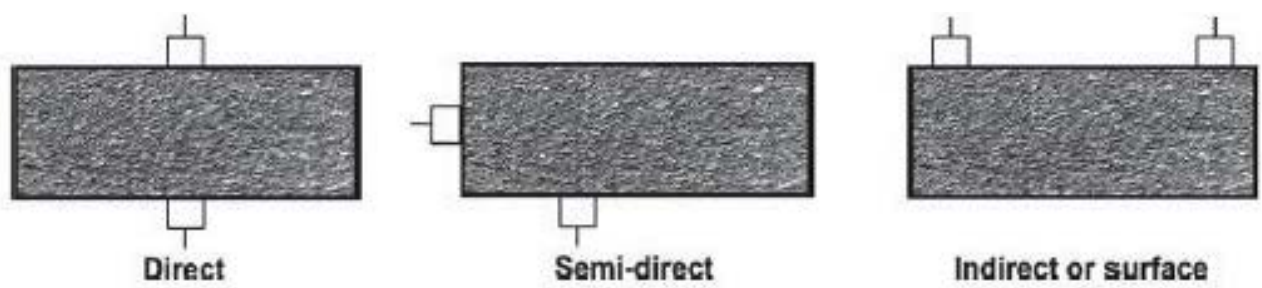

Figure 1. The three types of measurement regarding the arrangement of the probes (Pundit Lab Operating Instructions)

\section{EXPERIMENTAL STUDIES}

Blue Mosque is constructed in between 1609-1616, with its 6 minarets. The laboratory experiments are applied on the stones of the minaret which is under restoration whereas the site investigation is carried on the other 5 minarets of the mosque. The two of those five minarets (M1 and M6) have a height of 57 meters with two balconies; whereas the other three ones (M2, M4, M5) are 66 meter tall with 3 balconies. The minarets are stone masonry constructions. Figure 2 illustrates the settlement of the minarets of the Blue Mosque. While this study is being carried, the honeycomb part of the minaret M3 is removed due to the restoration work. The ultrasound, Schmitt and the compressive strength tests are carried on the stones removed from the honeycomb and will not be reused after the restoration. Besides, ultrasound testing is done on the other five minarets on the site.

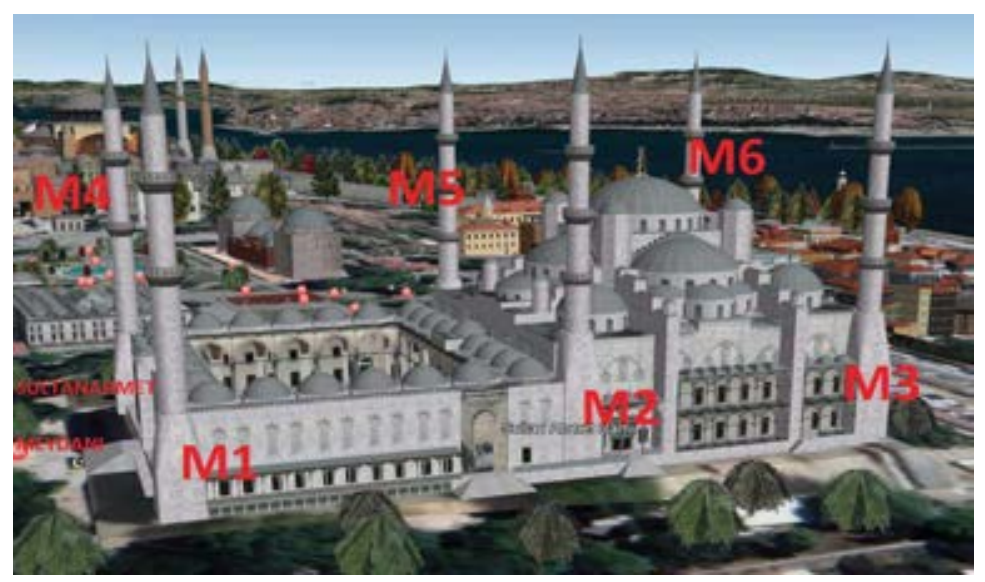

Figure 2. Blue Mosque and the settlement of its minaret 


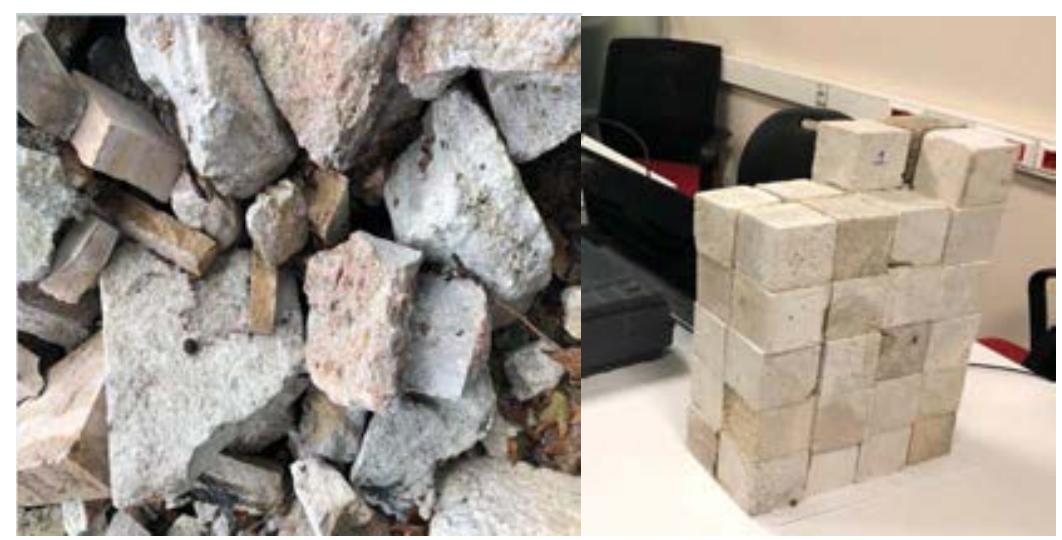

Figure 3. The debris removed from the minaret M3 and the cubic specimens obtained by cutting them

Figure 3 shows the debris removed from the minaret M3 and cut to the appropriate shape for the compressive strength test. The $7 \times 7 \times 7 \mathrm{~cm}$ and $5 \times 5 \times 5 \mathrm{~cm}$ cubic pieces, which are referred as "the large samples" and "the small samples" respectively in this paper, are obtained. First the large ones are worked. Five measurements are done for the each three pair of opposing surfaces to evaluate the $\mathrm{P}$ and $\mathrm{S}$ wave velocities, not only the numerical value but also with the wave forms. The $54 \mathrm{kHz}$ probes are used for the $\mathrm{P}$ waves and the $250 \mathrm{kHz}$ ones for the $\mathrm{S}$ waves. When it is completed, $\mathrm{P}$ wave velocity values are found to be reliable. However the $250 \mathrm{kHz}$ probes generate the $\mathrm{P}$ and $\mathrm{S}$ waves together, therefore the velocity value shown on the screen is not respectable and the wave forms are required to be inspected. Nevertheless it should be a detailed observation, since the $\mathrm{P}$ and $\mathrm{S}$ waves are not clearly detectable due to the limited dimension of the specimens. After the ultrasonic test, the Schmitt Hammer test is carried and then the density of each cubic piece is determined.

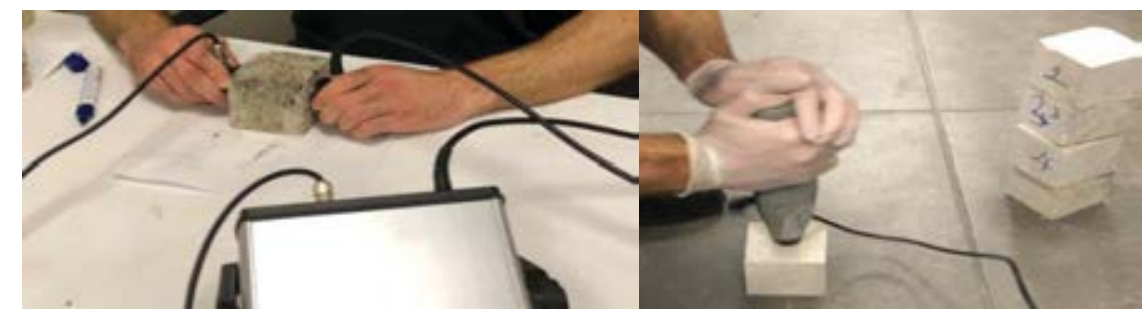

Figure 4. The ultrasound and Schmitt Hammer tests application

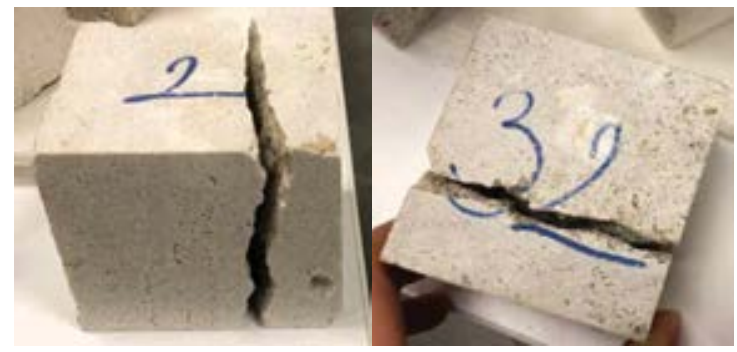

Figure 5. The samples cracked while the Schmitt Hammer test application

The Schmitt Hammer test is applied on each three non-reciprocal surfaces. After the ultrasonic test, Schmitt Hammer test and the density evaluation, compressive strength test is applied. The small samples are cracked during the Schmitt Hammer test, due to their dimensions, hence it is decided not to apply the test on them. Besides, the test applied on the large samples 
is not concluded in reliable correlation with the compressive strength test. Therefore, the Schmitt Hammer test results are not regarded in this study.

It is observed on the cracked specimens that, despite their soft surfaces they have quite stiff cores inside. This fact is considered as one of the reasons for not yielding reliable correlation between Schmitt Hammer test and compressive strength test results.

There are several ultrasound test measurements that resulted in remarkably different outcomes for each surface pairs of the same sample. Besides, it is thought that the compressive strength result is effected by the other two directions that the compression is not applied. Regarding these observations, three different methods are asserted in order to inspect the correlation between the $\mathrm{P}$ wave velocity and the compressive strength value.

\section{THE ANALYSES}

The analyses are launched after collecting the data from the previously mentioned tests. The $\mathrm{S}$ wave velocities are determined by observing the wave forms, then the regression analysis is carried to evaluate the correlation of the data. First, the correlation between the $\mathrm{P}$ wave velocity and the compressive strength is inspected. Concerning the readings on different surfaces of the samples, the correlations between the compressive strength and the following three measurements are regarded respectively: $\mathrm{P}$ wave velocity related to the compressed surface; the mean value of the $\mathrm{P}$ wave velocity related to each surface; the minimum $\mathrm{P}$ wave velocity obtained from each surface.

As can be seen in Figure 6 and 7, the correlations are found to be $66 \%, 77 \%$ and $79 \%$ respectively.

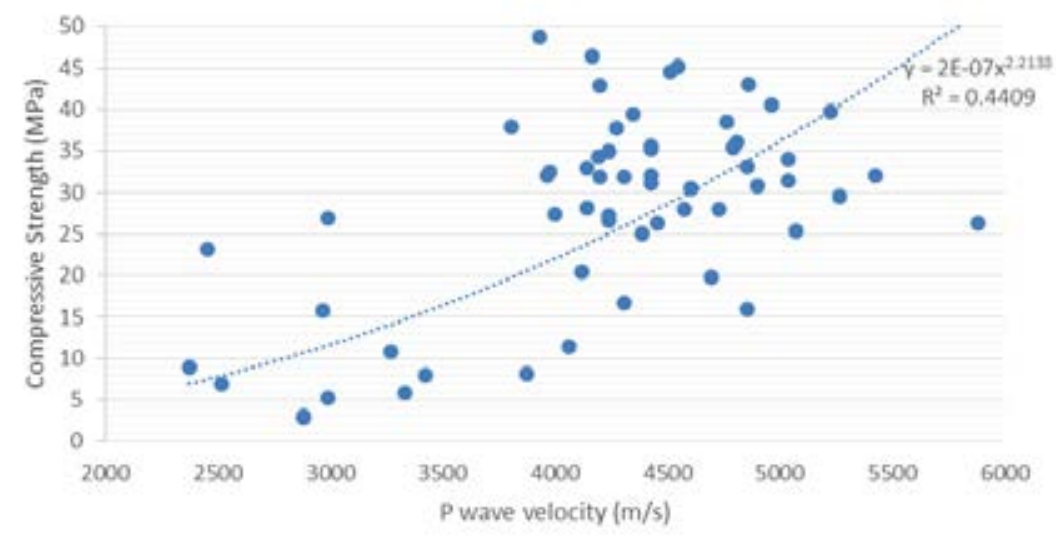

Figure 6 . The correlation between the compressive strength and $\mathrm{P}$ wave velocity related to the compressed surface

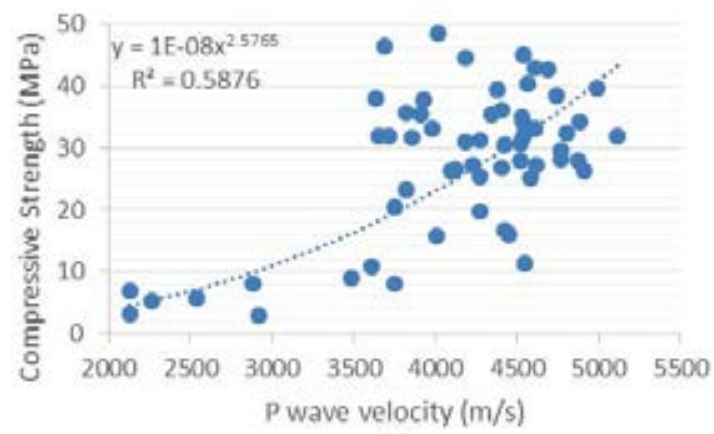

(a)

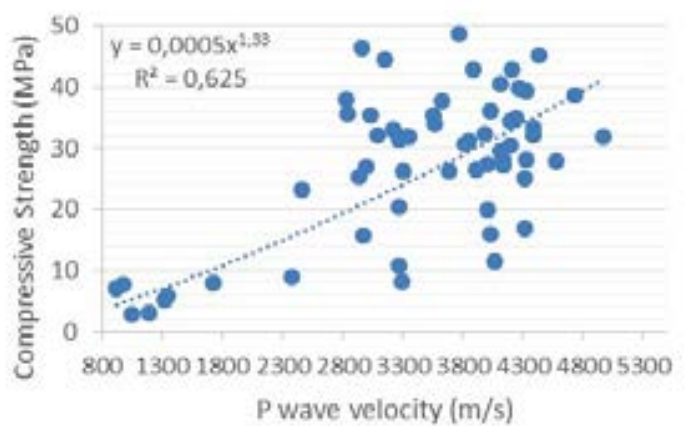

(b)

Figure 7. The correlation between the compressive strength and (a) The mean value of the P wave velocity related to each surface (b) the minimum $P$ wave velocity obtained from each surface 
Then, the correlation between the minimum $\mathrm{P}$ wave velocity obtained from each surface and the compressive strength is observed for the samples having $40 \mathrm{MPa}$ and below compressive strength. As Figure 8(a) points, the correlation increases up to $81 \%$ in that case. Consequently, the same analysis is carried for the samples with a compressive strength of $35 \mathrm{MPa}$ and below; $30 \mathrm{MPa}$ and below. The correlations are found to be $81 \%$ and $85 \%$ respectively (Figure 8(b), 8(c)). It is clear that the correlation is the same for the samples with a compressive strength of $40 \mathrm{MPa}$ and below and $35 \mathrm{MPa}$ and below; whereas it increases for the ones with $30 \mathrm{MPa}$ and below. However, there are 55 samples with $40 \mathrm{MPa}$ and below compressive strength out of 61 total samples; whereas only 32 of them have $30 \mathrm{MPa}$ and below compressive strength. It implies that, when only the samples with $30 \mathrm{MPa}$ and below compressive strength are considered, almost the half of the specimens are disregarded.

Figure $8(\mathrm{~d})$ represents that when the samples with a compressive strength of $25 \mathrm{MPa}$ and below are considered, the correlation decreases to $77 \%$ and there are only 18 samples tested.

Respecting the previously mentioned results, when the correlation and the number of the tested samples are regarded, the correlation between the compressive strength and the $\mathrm{P}$ wave velocity for the specimens with a compressive strength of $40 \mathrm{MPa}$ and below is found to be more reliable among the carried regression analyses.

Furthermore, the correlation between the $\mathrm{P}$ and $\mathrm{S}$ wave velocities is examined. As explained earlier, the $\mathrm{S}$ waves require a detailed eye observation on the waveforms. The observation declines that detecting the $\mathrm{S}$ wave velocity on a large cubic is easier and more reliable than that on a small one; since the wave path is longer. Therefore, the correlation between $\mathrm{P}$ and $\mathrm{S}$ waves is examined regarding the results obtained from the large samples. When the $\mathrm{P}$ wave velocity is considered, the mean value of the three surface readings is taken and as can be seen in Figure 9(a), it is found to be $86 \%$ correlated to the $\mathrm{S}$ wave velocity.

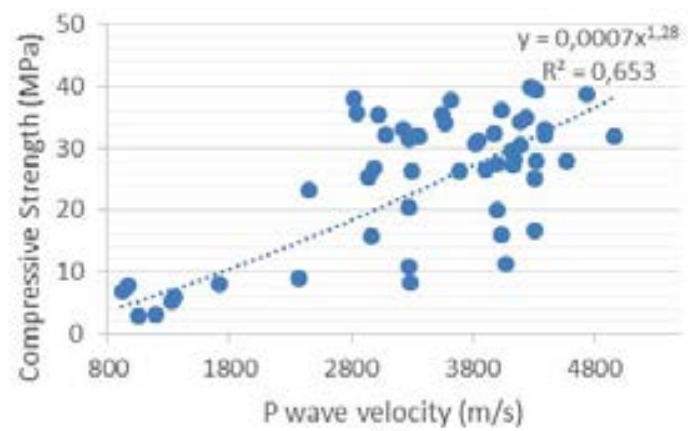

(a)

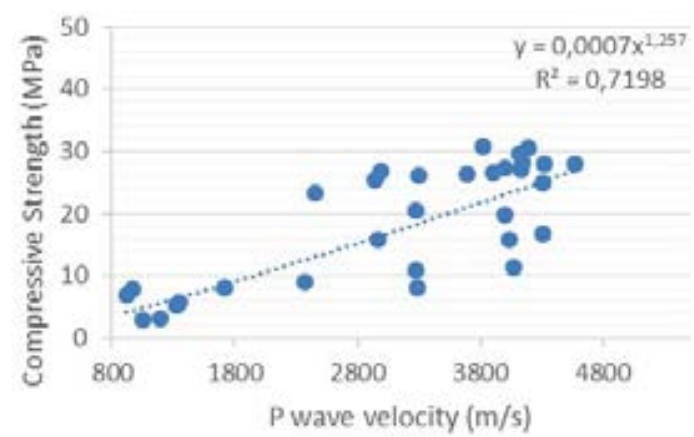

(c)

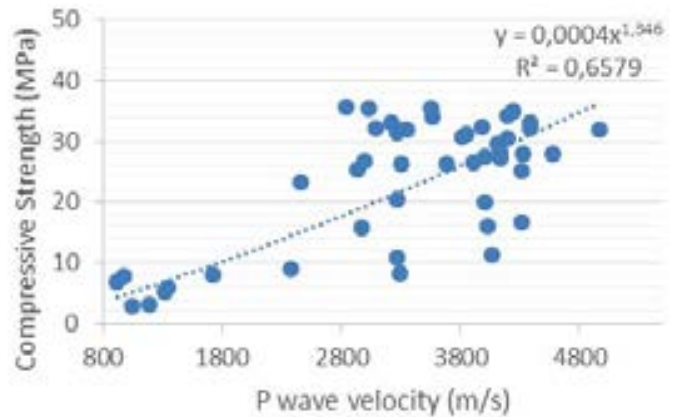

(b)

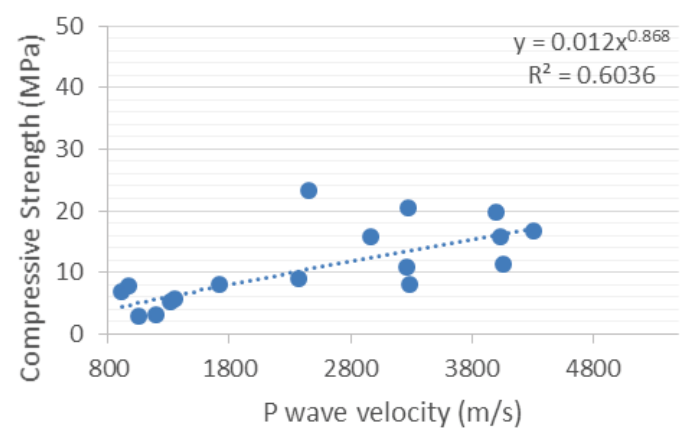

(d)

Figure 8. Correlation between the minimum $\mathrm{P}$ wave velocity from each surface and the compressive strength for the samples having $40 \mathrm{MPa}$ and below (a), $35 \mathrm{MPa}$ and below (b), $30 \mathrm{MPa}$ and below (c), $25 \mathrm{MPa}$ and below (d) 


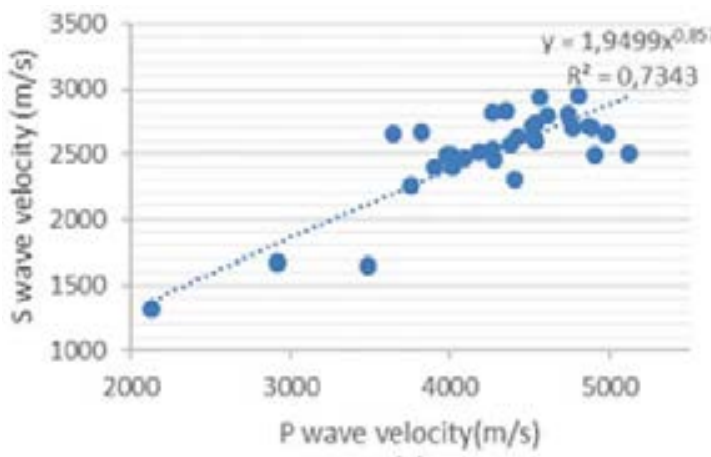

(a)

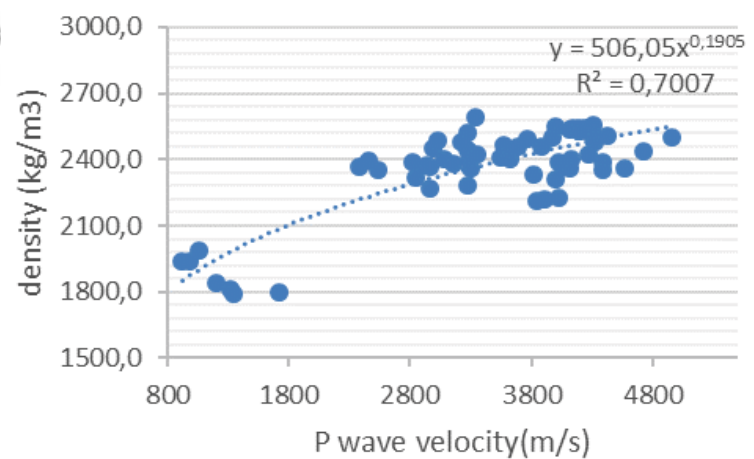

(b)

Figure 9. The correlation between (a) Vs and Vp (b) Density and Vp regarding three surfaces of the samples

Furthermore, the correlation between the density and the $\mathrm{P}$ wave velocity is examined. The minimum value of the $\mathrm{P}$ wave velocity readings from the three surfaces is regarded. First, the analysis is carried concerning the results taken from the samples with a compressive strength of $40 \mathrm{MPa}$ and below; however it is revealed that the correlation and its equation does not change significantly when all the samples are considered. Therefore, the equation found when all samples are analyzed is respected (Figure 9(b)).

The other five minarets M1, M2, M4, M5, M6 are observed by ultrasound testing equipment on site and the results are assessed regarding the laboratory test results mentioned above. The $54 \mathrm{kHz}$ and $250 \mathrm{kHz}$ probes are used for the site survey. Besides, the circular column at the core of the minarets where the stairs are rising, is measured by direct method using $54 \mathrm{kHz}$ probes.

\section{RESULTS}

First, the equations obtained from the laboratory tests are applied on the site survey results. The regression equation of the $\mathrm{P}$ wave velocity and compression strength correlation is adopted on the $\mathrm{P}$ wave velocity reading taken from the minarets on site to reveal the compressive strength of the material. The mean compressive strength values of each stone in a minaret is evaluated as following: $28 \mathrm{MPa}$ for M1, $10 \mathrm{MPa}$ for M2, $31 \mathrm{MPa}$ for M4, $10 \mathrm{MPa}$ for M5, 10 $\mathrm{MPa}$ for M6. Besides, the samples tested in the laboratory result in $28 \mathrm{MPa}$ of mean compressive strength. The compressive strength of different parts of each minaret is indicated in Figure 11, by a color scale. The color scale is illustrated in Figure 10.

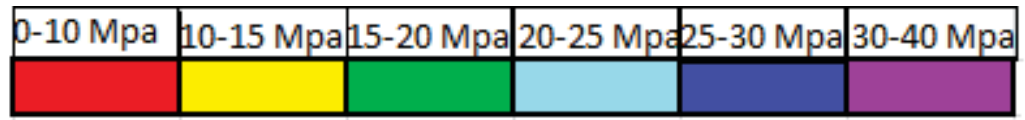

Figure 10. Color scale

\section{DISCUSSIONS}

This study offers the first application of compressive strength test on Blue Mosque stones, therefore it provides notable contribution to the literature when the future restoration works are considered. The samples tested in the laboratory result in $28 \mathrm{MPa}$ of a mean compressive strength and the compressive strength of the other five minarets on the site is detected part by part for each one.

It is found to have a correlation of $81 \%$ between $\mathrm{P}$ wave velocity and the compressive strength of the material. Besides, it is assumed that the nonhomogeneous structure has an effect on the compressive strength of the stones. 


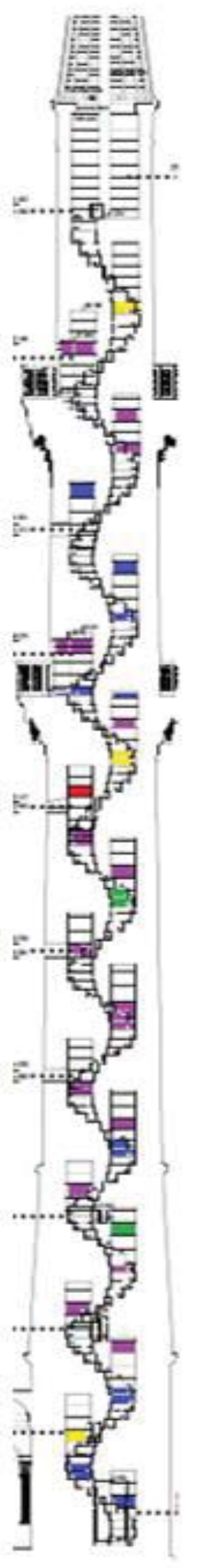

M1

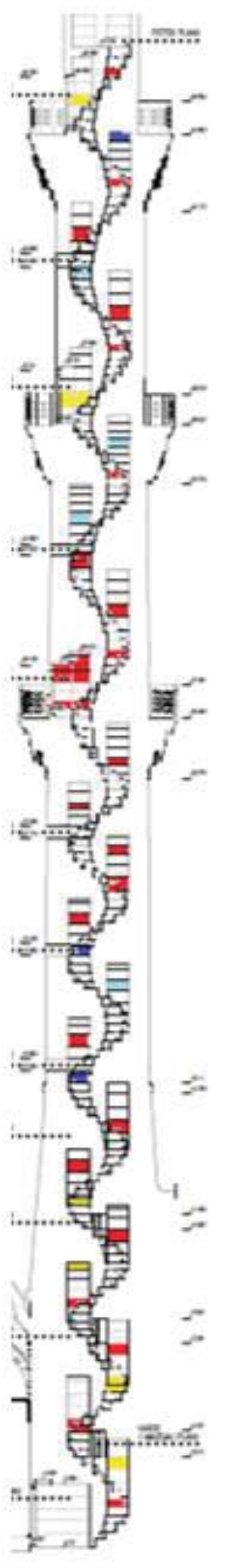

M2

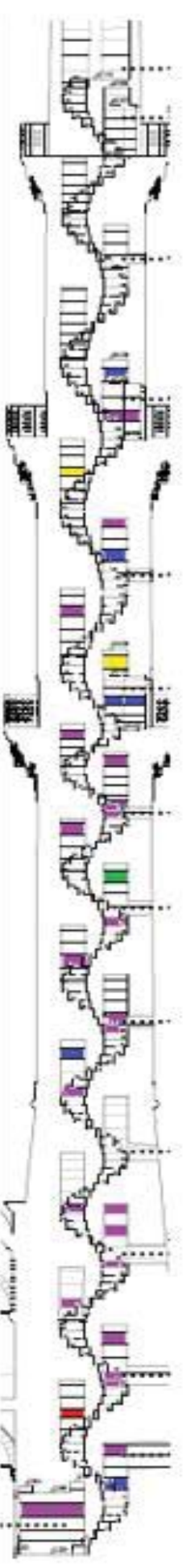

M4

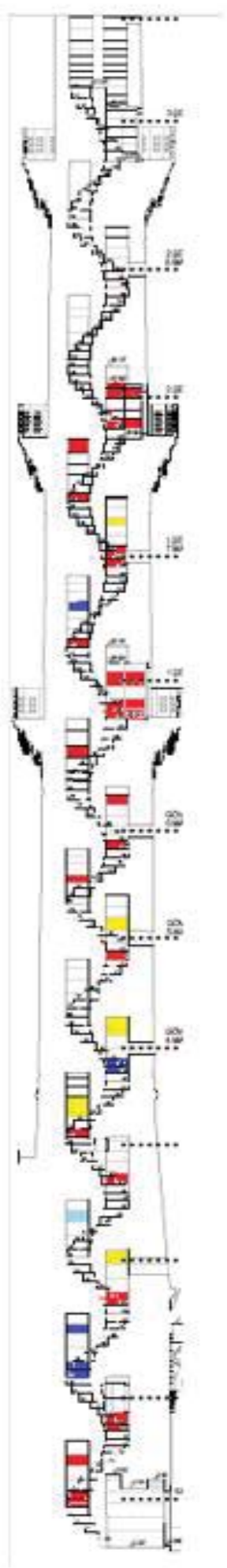

M5

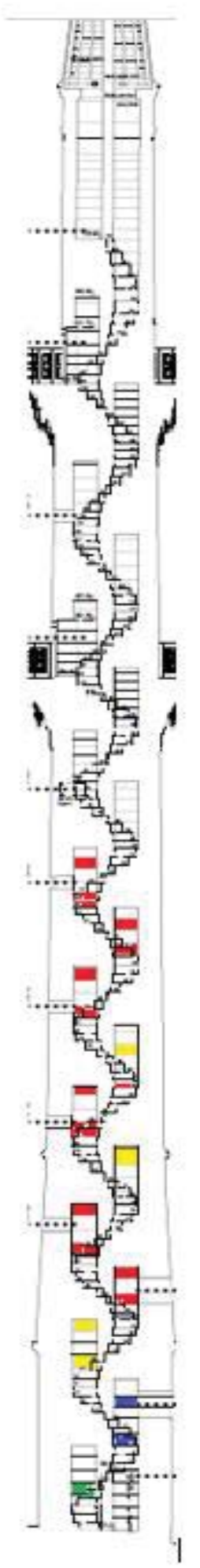

M6

Figure 11. The compressive strength of different parts of each minaret shown by a color scale 
Moreover, a number of stones with tough inner cores despite of their soft surfaces are blamed for the unreliable Schmitt Hammer test results. Additionally, the Schmitt Hammer test is observed to damage the samples.

The samples tested in the laboratory reveal that the $\mathrm{P}$ wave velocity obtained from different directions of the same cubic is significantly variable and the compressive strength result is highly effected by this diversity. The most reasonable outcome is obtained when the correlation between the minimum of the $\mathrm{P}$ wave velocity readings taken from 3 different surfaces of the sample and the compressive strength. However, it must be regarded that, the five minarets on site are not appropriate for taking the readings from all directions of the material.

When the $\mathrm{P}$ wave velocity that appears on the screen during the reading and the $\mathrm{S}$ wave velocity that obtained by an eye observation on the wave form are compared, the former one is found to be more respectable. Therefore, especially for the site surveys, the limitations of reading the $\mathrm{S}$ wave velocity should be concerned. This study offers the idea to determine the material property using the $\mathrm{P}$ wave velocity, neglecting the $\mathrm{S}$ wave velocity.

When the larger samples are considered higher level of correlation is found between the $\mathrm{P}$ and $\mathrm{S}$ wave velocities and the correlation between the $\mathrm{P}$ wave velocity and the density. This relationship may lead to the evaluation of $\mathrm{S}$ wave velocity and the density; therefore the shear and the elasticity modulus, employing the measured $\mathrm{P}$ wave velocity. This concept is left for a further study.

\section{REFERENCES}

[1] Proceq, Pundit Lab Operating Instructions, Proceq SA, Schwerzenbach, Switzerland, 2017. 